\title{
Topological Precision in the Thalamic Projection to Neonatal Mouse Barrel Cortex
}

\author{
Ariel Agmon, ${ }^{1}$ Lee T. Yang,' Edward G. Jones, ${ }^{1}$ and Diane K. O'Dowd ${ }^{1,2}$ \\ Departments of ${ }^{1}$ Anatomy and Neurobiology and ${ }^{2}$ Developmental and Cell Biology, University of California, Irvine, \\ California 92717
}

Somatosensory thalamus and cortex in rodents contain topological representations of the facial whisker pad. The thalamic representation of a single whisker ("barreloid") is presumed to project exclusively to the cortical representation ("barrel") of the same whisker; however, it was not known when this correspondence is established during early development, nor how precise the thalamocortical projection is at birth, before formation of barrels and barreloids. To answer these questions, we retrogradely labeled thalamocortical projection neurons in fixed brain slices from 0-8 d old (P0-PB) mice, by placing paired deposits of two fluorescent dyes in adjacent barrels or (before barrel formation) in adjacent loci in upper cortical layers. At all ages studied, a negligible fraction of the retrogradely labeled cells was double labeled, implying that branches of single thalamocortical axons never extended within layer IV over an area wider than a single barrel. In PO preparations, $70 \%$ of paired dye deposits placed $75-200 \mu \mathrm{m}$ apart resulted in statistically significant segregation of labeled cell clusters in the thalamus. Quantitative analysis indicated that on P0 about $70 \%$ of thalamocortical axons were within 1.3 presumptive barrel diameters from their topologically precise target. In P4-P8 preparations, the great majority of thalamic cells retrogradely labeled from a single barrel were found in a single barreloid, implying a 1:1 projection of barreloids to barrels. The postnatal increase in topological precision was reproduced by a computer simulation, which assumed that many aberrant axons corrected their initial targeting error by extending terminal arborizations asymmetrically, towards the center of their appropriate barrel.

[Key words: barrel cortex, postnatal development, thalamocortical, corticothalamic, somatotopy, confocal microscopy, DI-l, double labeling]

A common feature of sensory projections in the adult vertebrate nervous system is the precise topological (or "somatotopic") mapping of peripheral receptor sheets onto central brain structures (Udin and Fawcett, 1988; Holt and Harris, 1993). A strik-

\footnotetext{
Received Apr. 1, 1994; revised July 15, 1994; accepted July 19, 1994.

We thank Drs. Ken Miller and Ron Meyer for helpful discussions and comments on the manuscript. This work was supported by Grants NS30109, NS21377, and NS27501 from the National Institutes of Health, U.S. Public Health Service, and by a Bank of America-Giannini Foundation Fellowship to A.A. Confocal microscopy and image analysis were carried out in the Lucille M. Baumgaertner Molecular Neurobiology Imaging Laboratory, U.C. Irvine

Correspondence should be addressed to Aricl Agmon at the above address.

Copyright (c) 1995 Society for Neuroscience $0270-6474 / 95 / 150549-13 \$ 05.00 / 0$
}

ing example is found in the rodent trigeminal pathway, in which somatotopic representations of the facial vibrissae are found in the trigeminal nuclei of the brainstem (Belford and Killackey, 1979a; Ma, 1991) in the ventrobasal complex of the thalamus (VB) (Van der Loos, 1976; Ivy and Killackey, 1982) and in layer IV of the primary somatosensory cortex (Woolsey and Van der Loos, 1970). In each of these structures, individual whiskers are mapped onto discrete cytoarchitectural domains (called "barreloids" in the thalamus and "barrels" in the cortex), which as a group constitute a topological replica of the whisker pad. The somatotopic pattern emerges during early development in ascending order along the neuraxis (Belford and Killackey, 1979b; Killackey et al., 1990) and can be modified by surgical (Jeanmonod et al., 1977; Andres and Van der Loos, 1985; Woolsey, 1990) or genetic (Van der Loos and Dorfl, 1978; Welker and Van der Loos, 1986) manipulations of the whisker-pad, suggesting that the pattern is induced by the afferent axons, rather than by a blueprint intrinsic to the central structures themselves. This interpretation is further supported by the appearance of a whisker-pad pattern in the distribution of afferent terminations before a corresponding histochemical or cytoarchitectural pattern is evident postsynaptically (Erzurumlu and Jhaveri, 1990, 1992; Jhaveri et al., 1991).

How topological projections are formed is unknown. Possible mechanisms include (1) contact guidance, that is, continuous preservation of topology by the axons from origin to target (Horder and Martin, 1978); (2) initial profuse arborization of axon terminals, followed by pruning of overlapping terminations through activity-dependent competition (Willshaw and von der Malsburg, 1976; Miller, 1990); (3) guidance of axons by target-derived signals directly to their final position (Sperry, 1963; Gierer, 1987); (4) mutual recognition between terminals of axons originating from neighboring cells (Hope et al., 1976). In a recent study of neonatal mouse barrel cortex (Agmon et al., 1993) we found that developing thalamocortical axons do not branch widely within layer IV with subsequent retraction, but from the start arborize locally, forming spatially periodic clusters of tcrminations of gradually increasing complexity. In addition, thalamocortical axons ascend from the deep layers into layer IV in radial trajectories, implying that topological order (a "protomap") is first established in the deep layers, and is projected from there onto layer IV. In the present study we examined directly the topological order in the thalamocortical projection on postnatal days $0-8$, by retrogradely labeling clusters of thalamocortical projection neurons from dual dye deposits placed in close proximity in the upper cortical layers. The resulting pattern of retrogradely labeled cells in VB implied that a high degree of topological precision exists in the thalamo- 

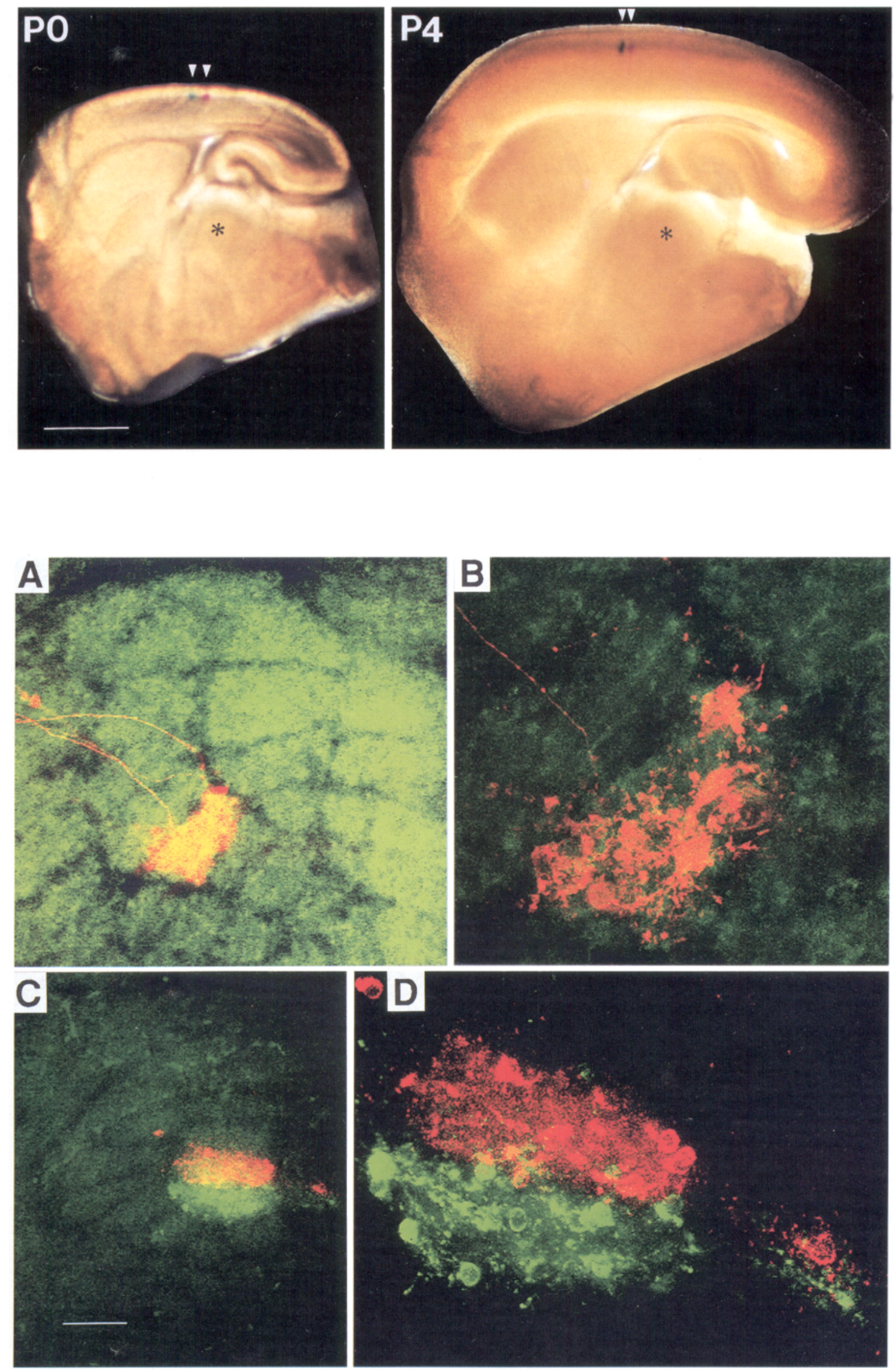
cortical projcction by birth, and that a one-to-one correspondence of barreloids to barrels is found by postnatal day 4 .

\section{Materials and Methods}

Slice preparation. Timed-pregnant female ICR mice (Harlan SpragueDawley) were monitored at $12 \mathrm{hr}$ intervals to determine the time of birth. Pups from 0 to $8 \mathrm{~d}$ postnatal (P0-P8, P0 being the first $24 \mathrm{hr}$ after birth) were anesthetized by hypothermia ( $\mathrm{P} 4$ and younger) or by halothane inhalation (P5 and older) and decapitated. Brains were rapidly removed and sliced at a thickness of 800 or $600 \mu \mathrm{m}$ on a Vibroslicer (Campden Instruments), in a plane that preserves thalamocortical connectivity (Agmon and Connors, 1991).

Dye injections. Freshly cut slices were placed in a petri dish, submerged in ice-cold physiological saline and transilluminated; at all ages studied VB was clearly delineated, and in P4 and older animals, cortical layer IV appeared as a distinct dark lamina, often broken into rectangular patches corresponding to individual barrels (Agmon and Connors, 1991). Two lipophilic carbocyanine dyes were used simultaneously as retrograde tracers: $\operatorname{DiIC}_{18}(3)$ [DiI(3), 1, 1'-dioctadecyl-3,3,3',3'-tetramethylindocarbocyanine perchlorate, catalog \#D-282, Molecular Probes, Eugene, OR] and $\mathrm{DiIC}_{18}(5)$ [DiI(5), 1,1'-dioctadecyl-3,3,3',3'-tetramethylindodicarbocyanine perchlorate, catalog \#D-307, Molecular Probes]. Paired dye deposits were injected under stereomicroscopic control through glass micropipettes filled with solutions of $0.25-0.5 \%$ dye in dimethyl formamide (DMF, Malinckrodt, Chesterfield, MO), using a Picospritzer II (General Valve, East Hanover, NJ). Dye was placed approximately $150 \mu \mathrm{m}$ deep into the anterior surface of the slice. In P4-P8 slices (Fig. 1 , right), paired injections were placed at the centers of adjacent barrels. In P0-P2 slices (Fig. 1, left), paired injections were placed 150-200 $\mu \mathrm{m}$ below the pial surface, a depth corresponding to the lower part of the undifferentiated cortical plate (Agmon et al., 1993), and between 50 and $200 \mu \mathrm{m}$ apart horizontally; distances were measured with an eyepiece reticle and later verified by measurement off photomicrographs. Individual dye deposits in $\mathrm{P} 0-\mathrm{P} 2$ slices were $50-80 \mu \mathrm{m}$ wide in the horizontal dimension of the cortex; in the vertical dimension, however, they often extended up to $200-250 \mu \mathrm{m}$, probably due to extracellular spread of dye along radial elements. Thus, some dye was no doubt available for uptake immediately below the lower border of the undifferentiated cortical plate, where the growing tips of most thalamocortical axons are located on P0 (Agmon et al., 1993). Following injections, slices were immersed overnight in $4 \%$ paraformaldehyde in $0.1 \mathrm{M}$ phosphate buffer (PB). Slices were then transferred to vials containing $0.2 \%$ sodium azide in $0.1 \mathrm{M} \mathrm{PB}$ and incubated at $37^{\circ} \mathrm{C}$ for at least 3 weeks before imaging; longer incubation periods did not seem to change the observed labeling patterns.

Measurements. Immediately after dye injection, slices were photographed under bright-field illumination at low $(1-4 \times)$ and medium $(10$ $20 \times$ ) power. Low-power photomicrographs were used for measuring the circumference of the slice along the white matter, between two reproducibly identifiable points (the medial edge of the alveus and the ventral edge of the external capsule), to determine the extent of cortical expansion between $\mathrm{P} 0$ and $\mathrm{P} 4$. Medium-power photomicrographs were used for measuring the laminar position, width and separation of dye deposits. Measurements were done on a digitizing tablet using sigmasCAN software (Jandel Scientific).

Confocal imaging. For confocal imaging, slices were whole mounted in $0.1 \mathrm{M}$ phosphate buffer between two glass coverslips and imaged with a Nikon Optiphot inverted microscope coupled to a Bio-Rad MRC-
600 dual-channel, dual-laser confocal system. Autofluorescent barreloid boundaries were imaged at a single focal plane under blue-green ( 488 $\mathrm{nm}$ ) or green (514 nm) excitation (see Agmon and Connors, 1991, Fig. 3; Senft and Woolsey, 1991c, Fig. 2); resolving well-defined barreloid boundaries usually required averaging 40 or more scans. DiI(3)-labeled structures were excited with the green $(514 \mathrm{~nm})$ line of an argon laser, and imaged through the GHS filter block (540 dichroic reflector, 550 barrier filter). DiI(5)-labeled structures were excited with the red (647 $\mathrm{nm}$ ) line of a krypton-argon laser, and imaged through the RHS filter block ( 660 dichroic reflector, 680 barrier filter). Using these filter blocks, the two dyes were imaged sequentially. In a later phase of the study a custom-designed set of filter blocks (Chroma Technologies, Brattleboro, VT) was used, which allowed simultaneous or interleaved imaging of both dyes. To image the full thalamocortical pathway, a $10 \times, 0.5 \mathrm{NA}$ objective was used. From each field of view, multiple optical scctions were digitally superimposed, the resulting image printed using a Sony Mavigraph video printer, and montages reconstructed from partially overlapping fields of view. To image retrogradely labeled cell clusters in VB, a $20 \times, 0.75$ NA objective was used. Stacks of 20-50 optical sections were imaged at $1-2.5 \mu \mathrm{m}$ increments. The resulting images were imported into a Microvoxel workstation (Indec Systems, Capitola, CA), reconstructed as three-dimensional shaded-surface objects, and printed on a videoprinter. For subsequent analysis, the three-dimensional coordinates of each cell were measured off the stack of optical sections, using Microvoxel. Quantitative analysis of the retrograde labeling pattern in the thalamus was carried out with MATHCAD software (Mathsoft, Cambridge, MA). Throughout this report, DiI(3)-labeled structures are pseudocolored green and DiI(5)-labeled structures are pseudocolored red.

Simulation. VB was simulated, using MATHCAD software, as an array of $30 \times 24$ cells, divided into $5 \times 4$ barreloids of $6 \times 6$ cells each. The cortical target of VB was simulated as an identical array. Each simulated thalamic cell was assumed to project to a cortical position calculated by adding an error vector to its thalamic position. The error vectors were randomly distributed in a two-dimensional gaussian distribution with a standard deviation of 1 barrel diameter, as suggested by our experimental results. Two adjacent barrels at the center of the cortical array were assumed to contain dye deposits. A P0 VB cell was considered labeled if its axon in the cortex was within one-third an equivalent barrel width from a simulated dye deposit. A P4 axon was assumed to have elaborated an asymmetrical terminal arbor 1 barrel diameter wide, directed towards the center of its correct barrel. In other words, simulated axons that on $\mathrm{PO}$ were up to 1 barrel diameter away from the center of an injected barrel were assumed labeled on P4, on condition that they originated in the barreloid corresponding to that barrel.

\section{Results}

\section{Data selection criteria}

A total of 133 mice, aged P0-P8, were used in this study, yielding 86 slices with retrogradely labeled cells in the thalamus. Of these, slices were chosen for analysis based on two criteria. (1) A total of at least 20 cells were retrogradely labeled, with at least 5 cells labeled by each dye (with the exception of P6-P8 slices, which were analyzed when they included at least 5 labeled cells from at least one dye deposit). (2) When viewed under bright-field illumination after the incubation period, the dye deposits in the

Figure 1. Dye deposits in fixed thalamocortical slices. White arrowheads point to the two dye deposits; DiI(3) appears as a red spot and DiI(5)
as a blue-green spot. In the P4 slice, layer IV is clearly visible as a dark lamina; the two dye deposits were placed in the centers of adjacent barrels,
not identifiable on the photograph. Asterisks denote the position of VB. Scale bar, $1 \mathrm{~mm}$.
Figure 2. Correlation between barrels and barreloids. Confocal micrographs of the dorsal part of VB in a P8 $(A, B)$ and a P4 $(C, D)$ slice, imaged
at low $(A, C)$ and high $(B, D)$ power. Dil(3)-labeled cells and autofluorescent barreloids, are pseudocolored green; DiI( $(5)$-labeled cells are pseudocolored
red. The yellow/orange color in $A$ and $C$, and near the red/green border in $D$, is due to photographic overlap of red and green, not to double-labeled
cells. Both preparations were labeled with two tracers placed in adjacent barrels; however the DiI(3) label in the P8 preparation $(A, B)$ did not
reach the thalamus, probably due to truncation of axons. Four rows of barreloids are visible in $A$, three rows in $C$. Labeled axons are seen exiting
the barreloid in $A$ and $B$; labeled axons are not visible in $C$ and $D$ due to the higher contrast used in printing these images. In $A$ and $B$, all labeled
cell bodies are confined to one barreloid (all label outside this barreloid is in axons or dendrites). In $D$, the pair of DiI(3) and DiI(5) labeled cells
at the bottom right were probably labeled due to spread of dye into the adjacent row of barrels within the depth dimension of the slice; the DiI( $(5)$
labeled cell at the top left is likely a true aberrant. Dorsolateral is up, ventrolateral is left in all panels. Scale bar: $A$ and $C, 100 \mu \mathrm{m} ; B$ and $D, 33 \mu \mathrm{m}$. 
cortex showed no significant spread, as judged by comparison with photographs taken immediately after dye injections. The final sample consisted of 24 slices, from P0 $(n=10)$, P2 $(n=$ 4), P4 $(n=6), \mathrm{P} 6(n=2)$, and P8 $(n=2)$.

\section{Dil(5) as a neuronal tracer}

To our knowledge this is the first detailed report of $\operatorname{DiI}(5)$ as a neuronal tracer, so a short consideration of its properties is in order. Although there was no apparent difference in the diffusion propertics of the two dyes, DiI(5) consistently yielded sharper and brighter images than DiI(3). This was due to several factors. DiI(5) has a $50 \%$ larger absorption coefficient, and about 10 fold higher quantum yield, compared to DiI(3) (Sims et al., 1974), making it about 15 times brighter under equal conditions of dye concentration and illumination intensity. More importantly, compared with DiI(3) its absorption and emission peaks are shifted about $100 \mathrm{~nm}$ towards the red, resulting in a large reduction in both light scattering and tissue autofluorescence. The main drawback of $\operatorname{DiI}(5)$ as a neuronal tracer is that conventional sources of excitation (e.g., mercury lamps) do not have a strong output in the wavelengths needed; however, its excitation peak is very close to the red line of the krypton-argon laser, which was used as an excitation source in the present study. In addition to the advantages of DiI(5) as a single tracer, the combination of $\operatorname{DiI}(3)$ and $\operatorname{DiI}(5)$, with the appropriate laser excitation sources, was found to be a particularly powerful tool for double labeling. Since the two dyes exhibit a wide separation in both excitation and emission spectra, the appropriate filter combinations produced very good separation between the two channels. In our hands, coupling ("bleed-through") between the two channels occurred only at very high excitation intensities, and when it occurred it was easy to detect, since labeled cells in the coupled channel were always much fainter than labeled cells in the direct channel.

\section{Correlation between barreloids and barrels on P4-P8}

The topological equivalence of barrels and barreloids implies an underlying one-to-one mapping of single barreloids to single barrels; however, it was not known how early in development such a one-to-one correspondence exists. To determine this, we retrogradely labeled VB cells in P4-P8 preparations from small deposits of $\operatorname{DiI}(3)$ and $\operatorname{DiI}(5)$ placed at the centers of adjacent barrels (Fig. 2). In the same slices, barreloids in VB were visualized by their autofluorescence. Retrogradely labeled cell clusters were usually found in the dorsolateral quadrant of VB, which is known to contain the five rows of large barreloids representing the large facial whiskers (Ivy and Killackey, 1982; Sugitani et al., 1990). In slices where both dye deposits gave rise to retrogradely labeled barreloids, the two barreloids were in most cases neighbors within the same row (Fig. 2C), indicating that our plane of section was roughly parallel to the rows of large barrels in the posteromedial barrel subfield (PMBSF, Woolsey and Van der Loos, 1970). In four P6-P8 preparations with clearly identifiable barreloid boundaries, $95 \%$ of all cells retrogradely labeled from a single dye deposit were within a single barreloid (Fig. $2 A, B$ ). In four P4 preparations with clearly identifiable barreloid boundaries, $87 \%$ of all retrogradely labeled cells were restricted to a single barreloid (Fig. $2 C, D$ ). We conclude that a highly accurate $1: 1$ projection of barreloids to barrels exists on P4, 24 hr (or less) after barrels are first evident in Nissl preparations (Rice and Van der Loos, 1977).

\section{The degree of topological precision on $\mathrm{PO}-\mathrm{P4}$}

The precise projection of barreloids to barrels found on P4 suggested that thalamocortical axons may already possess a high degree of topological order earlier in development. To determine the degree of topological precision on $\mathrm{PO}$, and to follow its progression in the first few days after birth, we retrogradely labeled thalamocortical projection cells in P0, P2, and P4 preparations from paired dye deposits in the cortex. Dye deposits on P4 were placed at the centers of adjacent barrels, with an average center-to-center separation of $140 \mu \mathrm{m}$. Measurements of the circumference of P0 and P4 slices showed an expansion of about $45 \%$ in the tangential dimension of the cortex between these two ages, suggesting that an "equivalent inter-barrel separation" on P0 was about $95 \mu \mathrm{m}$ (assuming that layer IV of barrel cortex expands tangentially at the same rate as the cortex as a whole). Accordingly, the horizontal separation between the two dye deposits was varied, in different P0 slices, between 75 and $200 \mu \mathrm{m}$ (center-to-center). Figure 3 shows representative retrogradely labeled clusters from three groups of preparations: "narrow P0" (deposits 75-120 $\mu \mathrm{m}$ apart, Fig. 3 left), "wide P0" (deposits 140-190 $\mu \mathrm{m}$ apart, Fig. 3 center) and P4 (deposits 120-150 $\mu \mathrm{m}$ apart, Fig. 3 right). Three main conclusions were drawn from these and similar preparations.

(1) The great majority of cells retrogradely labeled in PO-P4 slices were singly labeled, with only a small percentage doublelabeled (white cells in Fig. 3). In all 20 P0-P4 slices there were, on average, $2.6 \%$ double-labeled cells per slice (range 0-9\%), with no correlation between number of double-labeled cells and either age or distance between dye deposits in the cortex. Since P4 injections were placed in adjacent barrels, and some P0 injections were spaced at an equivalent interbarrel separation or less, lack of double-labeled cells implied that, on P0-P4, thalamocortical terminal arborizations within layer $I V$ do not extend over more than one barrel (or one presumptive barrel) in width.

(2) The clustering of retrogradely labeled cells according to label suggested that considerable topological precision already existed in the $\mathrm{PO}$ projection. The degree of overlap between the two cell clusters in VB depended, as expected, on the separation between the two dye deposits in the cortex - the further apart the dye deposits, the less the overlap between the two clusters (compare the left and middle columns in Fig. 3).

(3) Comparison of $\mathrm{P0}$ and $\mathrm{P} 4$ preparations suggested that a significant increase in the topological precision of the projection occurred between $\mathrm{P} 0$ and $\mathrm{P} 4$, since even when wide $\mathrm{P} 0$ preparations (with dye deposits 1.5-2 equivalent barrels apart) were compared with P4 preparations (with dye deposits one barrel apart), the P4 clusters were considerably more segregated.

\section{Quantifying the degree of segregation}

To quantify the conclusions in (2) and (3) above, a boundaryindependent measure of the degree of overlap was needed, since barreloid boundaries were rarely distinct on P2, and were never visible on $\mathrm{P0}$. This was achieved by defining two indices. The segregation index was defined as the ratio of the separation between the centers of mass of the two clusters of retrogradely labeled cells to the average dispersion within a cluster, the dispersion being the root mean square (RMS) of the distances of cells in each cluster from their center of mass, measured along the axis connecting the two centers of mass. The probability index was defined as the negative logarithm of the probability 
that a random redistribution of colors between all cells would result in segregation of label as high as observed or higher (see Appendix A for mathematical details). When indices calculated from $\mathrm{P} 0$ preparations were plotted against the distances between dye deposits (Fig. $4 A, B$ ), both indices showed a significant positive correlation with distance $\left(r^{2}=0.41, p<0.05\right.$, and $r^{2}=$ $0.59, p<0.01$, for the segregation and probability indices, respectively). The two indices were also found to be highly correlated with each other, most significantly for the $\mathrm{P0}$ data points (Fig. $4 C, r^{2}=0.79, p<0.01$, regression line not shown). Figure $4 C$ also illustrates that, in general, both indices increased between narrow $\mathrm{P} 0$ and wide $\mathrm{P} 0$, and between wide $\mathrm{P} 0$ and $\mathrm{P} 4$ preparations; however the increase between wide $\mathrm{P} 0$ and $\mathrm{P} 4$ was more pronounced in the probability index.

We used these data to estimate the topological precision of the thalamocortical projection on $\mathrm{P} 0$. This was done using two independent measures, derived respectively from the two indices. One measure for topological precision is the minimal separation, in the target structure, between dye deposits that would yield significantly segregated retrogradely labeled clusters in the source structure. Using a probability index of 1.3 (dotted horizontal line in Fig. $4 A$ ), equivalent to $p=0.05$, as a lower limit for statistical significance, we conclude from Figure $4 \mathrm{~A}$ that 7 out of 10 paired dye placements $75-200 \mu \mathrm{m}$ apart, including $50 \%$ of preparations with dye deposits $75-125 \mu \mathrm{m}$ apart, and $85 \%$ of preparations with deposits $125-200 \mu \mathrm{m}$ apart, gave rise to significantly segregated clusters of retrogradely labeled cells in VB.

A more direct measure for the topological precision of an axonal projection is its point spread function, that is, the probability density for an axon to arrive at any given point around its topologically precise target. A random targeting error would result in a gaussian-shaped point spread function; the RMS of this function, that is, the SD of the gaussian, is equal to the distance on either side of the target within which a given axon would arrive with $68 \%$ probability. We estimated the point spread function along the horizontal dimension of our slices by the reciprocal of the slope of the segregation index vs dye separation curve (Fig. $4 B$ ) (see Appendix B). This yielded a value of $125 \mu \mathrm{m}$, implying that, on average, $70 \%$ of the thalamocortical axons on $\mathrm{P} 0$ are within about 1.3 presumptive barrels from their topologically precise target, along one horizontal dimension.

The same method could not be used directly to calculate the RMS of the point spread function in P4 and older preparations, since the calculation assumed a random placement of the paired dye deposits along the horizontal plane, whereas in P4 and older slices our injections were preferentially placed in the centers of barrels. We therefore calculated the RMS of the point spread function in the adult barrel system theoretically, under the assumption of a perfect 1:1 projection of barreloids to barrels, and the further assumption that each thalamocortical axon branches homogeneously throughout the extent of its target barrel (Jensen and Killackey, 1987). The calculation (Appendix C) yielded an RMS of about 0.4 barrel diameters. We conclude that in mouse barrel cortex, up to threefold increase in topological precision occurs postnatally.

\section{Simulation}

To test the possibility that the P0-to-P4 increase in the degree of segregation of retrogradely labeled cells in the thalamus could be explained by extension of axonal arbors in the cortex, we constructed a geometric computerized model of the rodent VB, and simulated the effects of arbor extension on the degree of segregation in the thalamus. The simulation was guided by three basic assumptions (see Materials and Methods for additional details):

(1) On P0, all axons terminations in upper cortical layers were single, unbranched processes (Catalano et al., 1991, 1993; Senft and Woolsey, $1991 \mathrm{a}$; Agmon et al., 1993; Kageyama and Robertson, 1993).

(2) The probability that a given $\mathrm{P} 0$ axon will arrive at any given point in the cortex could be described by a gaussian centered around its topologically correct target (Senft and Woolsey, $1991 \mathrm{a}-\mathrm{c})$.

(3) From $\mathrm{P0}$ to $\mathrm{P} 4$ there was no change in the location of thalamocortical axonal trunks; however each axon extended an arbor in one of two modes: either symmetrically or asymmetrically, the latter being directed preferentially towards the center of its correct target barrel. In both cases the total horizontal extent of the arbor on P4 was constrained to slightly more than 1 barrel diameter.

In each run of the simulation, the two-dimensional coordinates of $\mathrm{PO}$ axons in the cortex were determined by applying a random walk algorithm to the coordinates of their cell bodies in the thalamus. The parameters of the random walk were chosen to produce a gaussian distribution of axon terminals in the cortex with an RMS of 1 barrel diameter, approximately equal to the experimentally observed RMS (see above). The resulting configuration of axons was then used to calculate the labeling patterns expected in VB from PO dyc deposits 0.75 and 1.5 barrels apart corresponding, respectively, to the experimental "narrow" and "wide" deposits (Fig. 4D, left and middle panels), and the labeling pattern expected from dye deposits in adjacent barrels on $\mathrm{P} 4$, after arbor extension has occurred (Fig. $4 D$, right panel). Allowing each axon to grow a symmetric arbor around its axonal trunk failed to reproduce the experimental results (not shown). However, allowing "aberrant" axons to correct their initial targeting error by extending an asymmetric arbor, directed towards the center of their correct target barrel, produced segregation patterns in VB that resembled the experimental data (compare Fig. $4 D$ with Fig. 3).

To test quantitatively whether our simulated results were consistent with the experimental data, we used the same indices previously applied to the experimental data to quantify the degree of segregation in the simulated patterns (Fig. $4 E$ ). As evident from comparison of Figure $4, C$ and $E$, the range of values attained by the indices of the simulated patterns were comparable to the experimentally observed ones, although somewhat more dispersed.

\section{Topological order along the thalamocortical pathway}

To examine the degree of topological order along the thalamocortical pathway, we prepared montages of the entire labeled pathway from $\mathrm{P0}(n=4), \mathrm{P} 2(n=4)$, and $\mathrm{P} 4(n=5)$ slices. Two representative montages, from $\mathrm{PO}$ and $\mathrm{P} 4$, are illustrated in Figure 5. The interpretation of these images required exclusion of a conspicuous bundle of labeled axons (between arrows) that was consistently observed to cross the main pathway diagonally, at the level of the internal capsule, and was invariably truncated shortly below the crossing point. Their ventromedial position in the white matter made it likely that these were corticofugal axons (Woodward et al., 1990; Miller et al., 1993; Bicknese et al., 1994). Focal dye placement at the truncated tips of these 


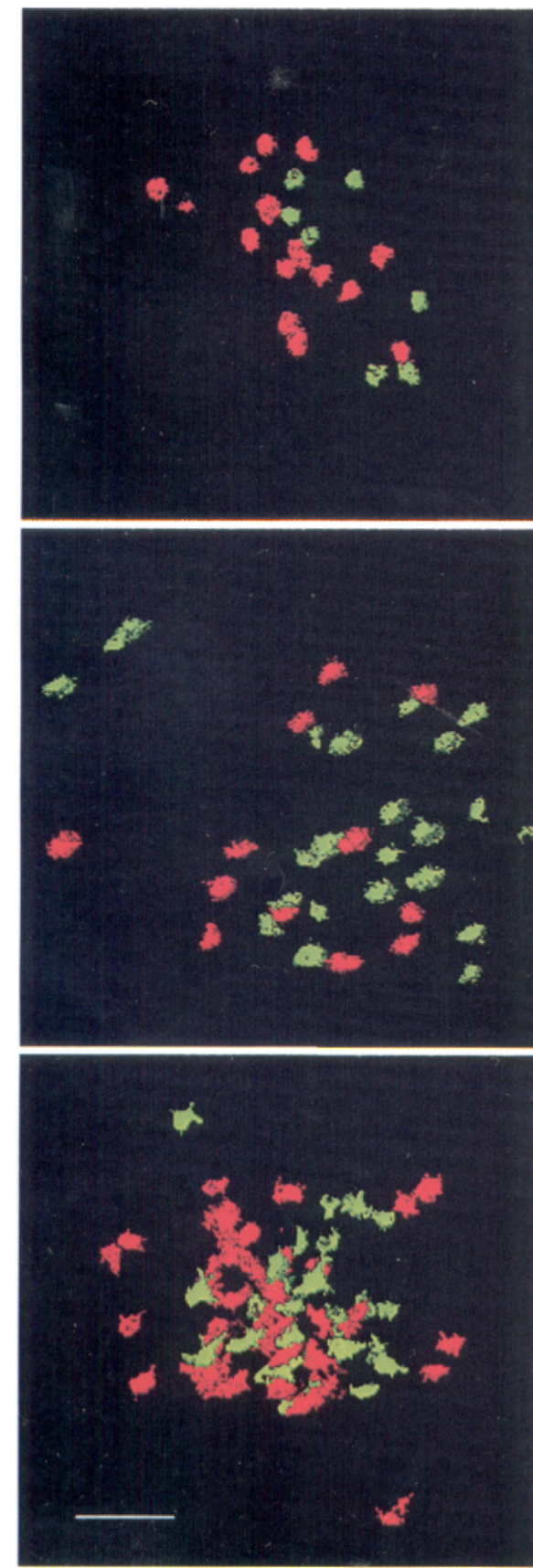

PO NARROW

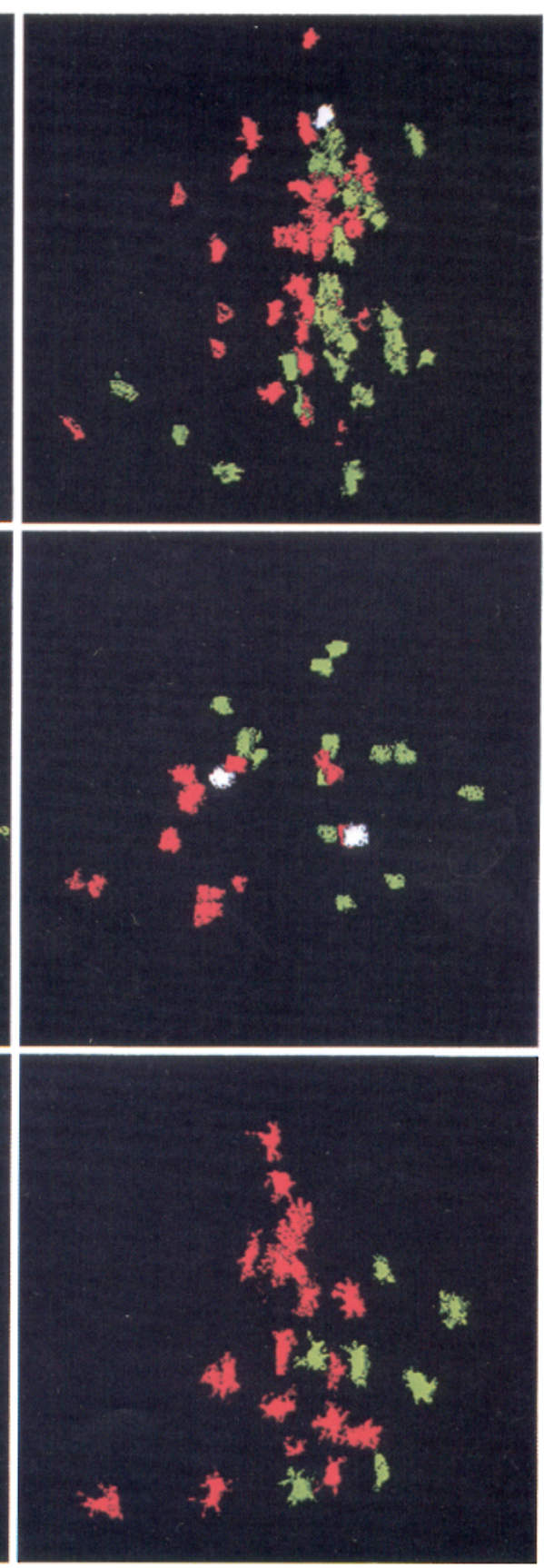

PO WIDE

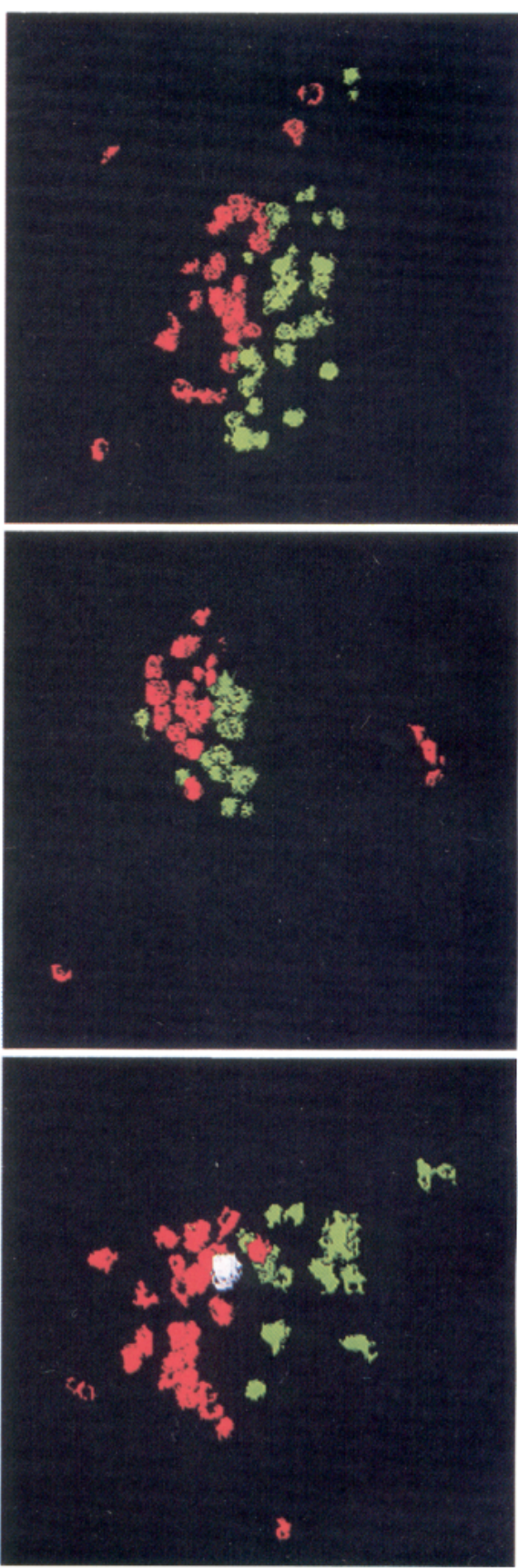

P4

Figure 3. Retrograde labeling patterns in VB resulting from dual tracer deposits in the cortex. Each panel is a three-dimensional reconstruction from stacks of confocal optical sections. DiI(3)-labeled cells are pseudocolored green, DiI(5)-labeled cells are pseudocolored red, and double-labeled cells are pseudocolored white. Left column, P0 preparations labeled from dual dye deposits 75-120 $\mu \mathrm{m}$ apart ("narrow"); middle column, P0 preparations labeled from dual dye deposits 140-190 $\mu$ m apart ("wide"); right column, P4 preparations labeled from dual dye deposits in adjacent barrels (120-150 $\mu \mathrm{m}$ apart). Note the increase in the degree of segregation between differentially labeled cells, from left to right. Panels are oriented with the border between clusters running approximately vertically; absolute orientations of different panels vary. Scale bar: $P 0,100 \mu \mathrm{m} ; P 4,75 \mu \mathrm{m}$.

fibers gave rise to retrograde labeling of many pyramidal cells in the deep cortical layers (not shown), thus confirming this identification. When these fibers were excluded, it was obvious even from a qualitative examination of the labeled pathway that the degree of segregation between the two labels was much lower as the fibers coursed through the upper striatum and the subcortical white matter than it was in the thalamus. Thus, thalamocortical axons retrogradely labeled from separate cortical loci were more intermixed along the pathway then they were at their origin, implying that resegregation of thalamocortical axons occurred in the vicinity of their target. A notable exception was found in the thalamic reticular nucleus (RTN) of P2 and older preparations: on these ages, thalamocortical axons passing through RTN gave rise to a plexus of terminations (between arrowheads), and within this plexus there was a clear segregation of terminations labeled with different dyes. 


\section{Discussion}

The present study addressed four central questions regarding the development of topological precision in the thalamocortical projection:

(1) What degree of topological precision exists in the thalamocortical projection at birth?

(2) How does this topological precision arise?

(3) What degree of topological precision exists in the mature thalamocortical projection and how does it compare with the precision at birth?

(4) What mechanisms underlie the postnatal refinement in topological precision?

\section{What degree of topological precision exists in the $P 0$ projection?}

Three previous studies have concluded that there is topological order in the thalamocortical projection of the neonatal rodent, with the degree of order qualified variably as "crude" (Naegele et al., 1988), "[with a] significantly greater degree of divergence [than in the adult]" (Crandall and Caviness, 1984), or "high" (Dawson and Killackey, 1985). These studies used a single retrograde tracer, with injections that usually involved the deep cortical layers and occasionally the subcortical white matter. We used double labeling, focal dye deposits restricted to the upper cortical layers, high-resolution confocal microscopy, and quantitative analysis, to reexamine these conclusions, and arrived at a quantitative estimate for the precision of the neonatal topology. On P0, $70 \%$ of paired dye deposits in the upper cortical layers, spaced 75-200 $\mu \mathrm{m}$ apart horizontally, resulted in statistically significant segregation of retrogradely labeled cells in VB, indicated by a probability index larger than 1.3 (Fig. $4 A$ ). A more direct measure was derived from the segregation index, since the rate of increase in this index, as a function of separation between the two dye deposits in the cortex, is the reciprocal RMS of the thalamocortical point spread function (Appendix B). Our data implied that, on $\mathrm{P0}$, about $70 \%$ of thalamocortical axons in the upper cortical layers were within $125 \mu \mathrm{m}$, or about 1.3 equivalent barrels, from their topologically precise target. (This value applies only to the spread along the horizontal dimension in our particular plane of section, which was roughly parallel to the rows of the PMBSF barrels.) Thus, the topology of the thalamic projection to the upper cortical layers of the mouse is highly precise at birth, although less precise than in the adult (see below). It should be noted that we are using the term "projection" in its morphological sense, without implying that thalamocortical afferents actually make synaptic contacts with cells in the upper layers of the neonatal cortex.

\section{How does the neonatal topological order arise during prenatal development?}

One way a topologically ordered projection could arise is by retention of the relative positions of axons along the pathway (Horder and Martin, 1978). If this was the case in the thalamocortical pathway, then the segregation along the pathway between thalamocortical axons labeled from two different dye deposits in the cortex should have been as good as, or better, than that in the thalamus. This was clearly not the case: in P0$\mathrm{P} 4$ preparations, cell bodies in VB were strikingly segregated by label, even though along the pathway axons were thoroughly mixed. In addition, examination of the trajectories taken by labeled thalamocortical axons within VB itself suggested that axons from a more medial barreloid are likely to course directly through more lateral barreloids on their way to the internal capsule (Figs. $2 A, 5$ ), precluding almost from the start any preservation of topological relationships along the pathway. That thalamocortical fibers do not maintain their nearest-neighbor relationships en route has been previously demonstrated in both somatosensory and visual systems (Nelson and LeVay, 1985; Bernardo and Woolsey, 1987; Miller et al., 1993). Thus, a process of active resegregation must occur prenatally, close to or within the cortex. In a previous anterograde labeling study (Agmon et al., 1993) we hypothesized that this resegregation process occurs in the deep cortical layers, since from the deep layers upwards thalamocortical axons follow a generally radial course. In the deep layers, thalamocortical axons run obliquely or horizontally and overlap to a considerable extent, therefore providing an anatomical substrate for competitive interactions. Alternatively, thalamocortical axons could be guided by molecular positional cues, similar to the molecular gradients conjectured to guide retinal fibers to and in the tectum (Stirling, 1991; Sanes, 1993).

\section{What is the topological precision of the mature} thalamocortical projection and how does it compare with the precision at birth?

The topological equivalence of the whisker-related patterns in the thalamus and cortex would suggest a precise anatomical projection between barreloids and barrels. Somewhat surprisingly, the exact degree of precision in the mature projection, that is, the fraction of thalamocortical axons in a given barreloid which project to the "correct" barrel, has not been previously determined; scant existing data suggest that this fraction is high but less than $100 \%$ (Land and Simons, 1985). Our data imply that by P4-P8 there is already a fairly accurate, but again not perfect, 1:1 projection of barreloids to barrels; whether any further increase in precision occurs between P8 and the adult is yet to be determined. As shown in Appendix C, the RMS of an "idealized" projection, in which $100 \%$ of the axons terminate in their correct barrel, would be about 0.4 barrel diameters, which is about threefold more precise than the experimentally observed point spread function in our P0 preparations.

\section{What mechanisms underlie the maturation of the topological map?}

Contrary to previous suggestions (Senft and Woolsey, 1991ac), elimination of exuberant branches from incorrect barrels was unlikely to have contributed to the postnatal increase in topological precision we observed, since at all ages studied dye deposits in adjacent cortical loci gave rise to a negligible fraction of double-labeled cells, implying little or no overlap between incipient terminal arborizations in adjacent (presumptive) barrels. This conclusion is also supported by anterograde labeling of thalamocortical axons in neonatal rodents (Agmon et al., 1993; Catalano et al., 1993), demonstrating that thalamocortical terminations on P0 arc unbranched or very sparsely branched, and that over the first few postnatal days they arborize focally within the incipient layer IV, but never over a horizontal extent wider than a single barrel. It is also unlikely that the improvement in topological precision was due to movement of cell bodies in the thalamus; this would have required cell bodies to rearrange according to the position of their axons in a distant target, and such retrograde transfer of positional information has not been documented. A more plausible explanation is that 
A. P.I. vs distance

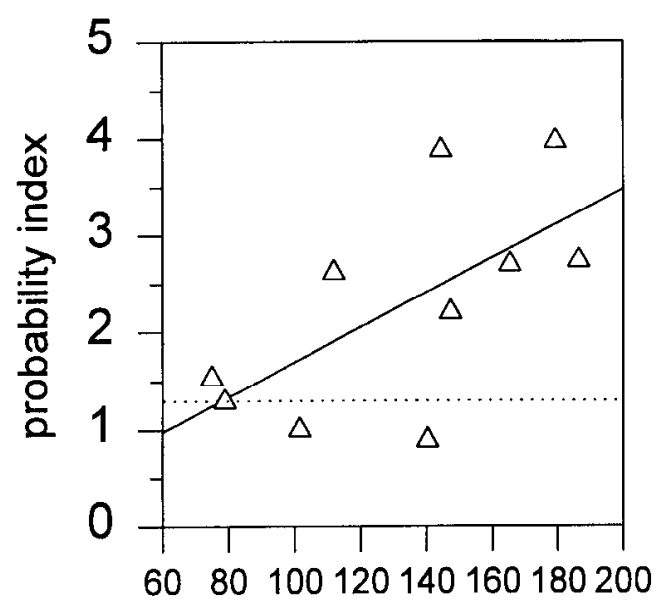

distance between dye deposits

C. experimental data

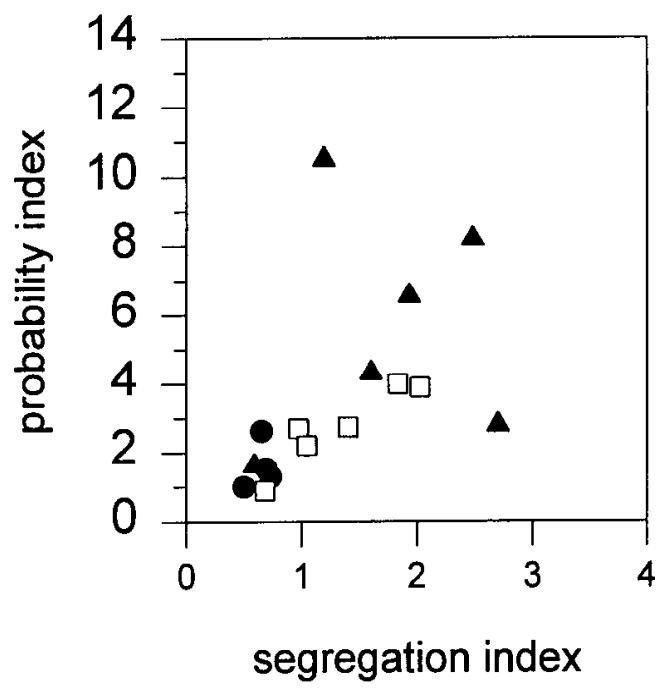

D. simulation
B. S.I. vs distance

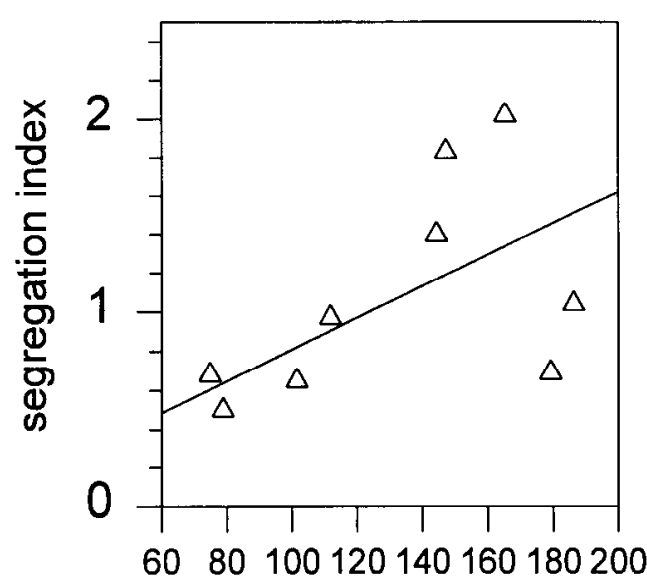

distance between dye deposits

E. simulated data

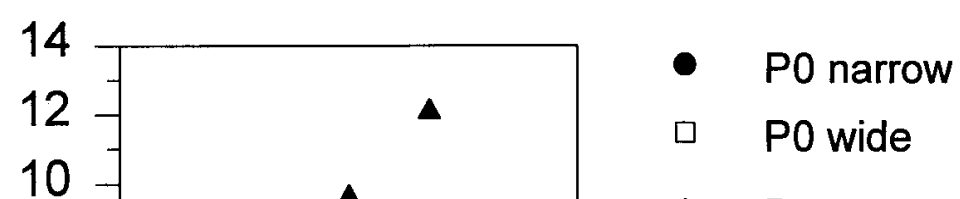

- P4

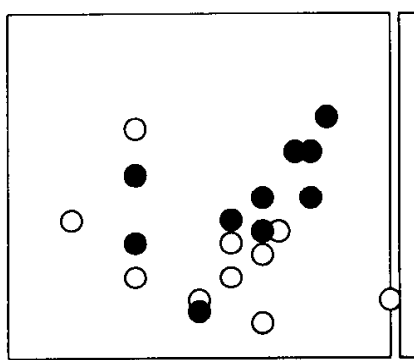

P0 narrow

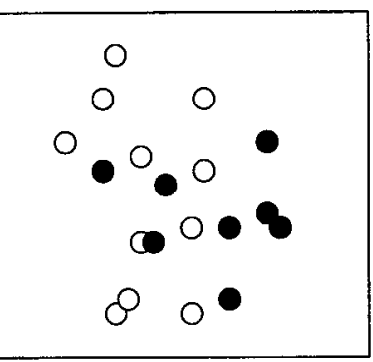

P0 wide

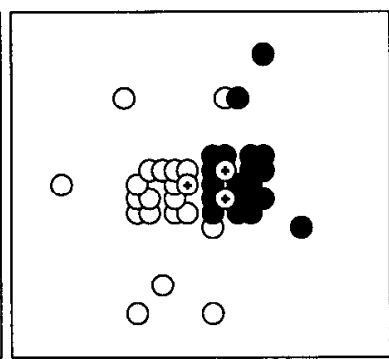

P4 
the changes we observed reflected directed growth of terminal arborizations in the cortex. In the simulation, redirection of aberrant axons towards their correct barrel by asymmetrical extension of arbors reproduced the observed increase in both indices in VB. Asymmetrical thalamocortical arbors, similar to those postulated here, have been demonstrated in both adult and neonatal rodent (Jensen and Killackey, 1987, Fig. 6; Lorente de Nó, 1922, Fig. 26; Agmon et al., 1993, Fig. 7D) and are reminiscent of course-correcting retinotectal axons in chick and rat (Thanos and Bonhoeffer, 1987; Nakamura and O'Leary, 1989; Simon and O'Leary, 1992b) and course-correcting retinothalamic axons in cat (Sretavan and Shatz, 1987).

Cues guiding this directed extension of thalamocortical terminal arbors are likely to be activity independent, since the whisker-related pattern develops normally despite neonatal blockade of sensory-evoked electrical activity in the barrel cortex (Chiaia et al., 1992; Henderson et al., 1992; Schlaggar et al., 1993). One possible mechanism is axon-axon recognition, mediated by a position-dependent chemotropic signal which is anterogradely transported along the axons and secreted from their terminals; the whisker-related pattern in the brainstem has been shown to depend on axonal transport (Chiaia et al., 1993). This does not rule out a possible role for activity-dependent competition, mainly in eliminating axons with an initial targeting error too large to be corrected, as has been proposed in the developing rat retinotectal projection (Simon and O'Leary, 1992a,b). Retention of aberrant axons would explain why whisker removal or blockade of postsynaptic activity in neonatal rats results in morphologically normal barrels, but an abnormally high fraction of layer IV cells with topologically incorrect receptive fields (Fox, 1992; Fox et al., 1993).

Somatotopy versus thalamotopy in the developing barrel cortex In newborn mice, a whisker-related pattern is not found in either cortex or thalamus; we consequently conclude that the thalamocortical projection on $\mathrm{PO}$ is not somatotopic but thalamotopic; that is, it is a topological mapping of the thalamus onto the cortical sheet, as yet unrelated to the periphery. Based on our experimental and simulated data, we can hypothesize the following sequence of events to account for the postnatal changes in topological precision. On or around P2, thalamic barreloids are formed, and thereby cells in VB acquire a whisker-specific identity. This identity is relayed to their axon terminals in the cortex, resulting in a logical partitioning of the axons into dis- crete groups (Senft and Woolsey, 1991c). Through mutual recognition between axons belonging to the same group, axons direct newly formed terminal branches towards the group's center of mass within incipient layer IV, thus forming whiskerspecific clusters of arborizations within layer IV. The result is a transformation of the continuous thalamotopic P0 map into a discrete somatotopic projection that reproduces the barreloid (and thus whisker) pattern in the plane of layer IV. We thus concur with the conclusion of Dawson and Killackey (1985) that in the rodent thalamocortical system "topographic order develops independently and precedes somatotopic order."

\section{Appendix A}

In the following, bold lettering designates three-dimensional vectorial entities. We assume two clusters of differentially colored cells, with $G$ green cells and $R$ red cells (double-labeled cells are treated as two cells of opposing colors occupying the same position in space). We detine the center of mass $\mathbf{C . M}$. GREEN $\left(\right.$ C.M. RED $_{\text {RE }}$ of all green (red) cells as the vectorial mean of their position vectors $\operatorname{CELL}_{1}$; that is,

$$
\text { C.M. }_{\text {GREN }}=\frac{1}{G} \cdot \sum_{i=1}^{G} \text { CELL }_{1} \text {. }
$$

The displacement $\mathrm{D}_{\mathrm{i}}$ of green cell $i$ is defined as the dot product

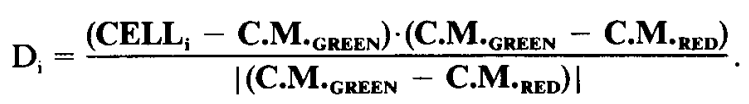

This is simply the signed distance of cell $i$ from the center of mass of its cluster, measured along the line connecting the two centers of mass. (The quantity in the denominator is the distance between the two centers of mass.) We then define the root-meansquare (RMS) displacement of all green cells as

$$
\operatorname{RMS}_{\mathrm{GREEN}}=\sqrt{\frac{\sum_{i=1}^{G} \mathrm{D}_{\mathrm{i}}^{2}}{G}} .
$$

RMS $_{\text {RED }}$ is similarly defined. Finally, we define the segregation index S.I. as

$$
\text { S.I.: }=\frac{\mid\left(\text { C.M. }_{\cdot_{\text {GREN }}}-\text { C.M.RED }_{\cdot_{\text {RED }}}\right) \mid}{1 / 2 \cdot\left(\text { RMS }_{\text {GREN }}+\text { RMS }_{\text {RED }}\right)} .
$$

To define the probability index, we first find an optimal plane of separation between the two clusters, that is, a plane which

\footnotetext{
Figure 4. Quantitative analysis of experimental and simulated labeling patterns in VB following dual dye deposits in the cortex. $A$, the probability index $(P . I$.$) , defined as the negative logarithm of the probability that the observed segregation occurred by chance, as a function of the distance$ between the two dye deposits in the cortex. Straight line is the calculated linear regression; $r^{2}=0.59, p<0.01$. Horizontal dotted line demarcates an index value of 1.3 ; points above this line represent preparations with a statistically significant segregation $(p<0.05)$. $B$, The segregation index (S.I.), defined as the ratio of the separation between the two retrogradely labeled clustered to the average dispersion within each cluster, as a function of the distance between the two dye deposits in the cortex. Straight line is the calculated linear regression, constrained to pass through the origin of axes; $r^{2}=0.41, p<0.05$. The reciprocal of the slope of this line, $125 \mu \mathrm{m}$, is an estimate for the root-mean-square (RMS) of the point spread function of the thalamocortical projection. $C$, The segregation and probability indices increased, on average, with the distance between the dye deposits (compare narrow P0 preparations, dye deposits about 1 equivalent barrel apart, with wide P0 preparations, dye deposits $1.5-2$ equivalent barrels apart), and with age (compare both groups of P0 preparations to P4 preparations, the latter with dye deposits 1 barrel apart). $D$, Simulated patterns of retrogradely labeled cell clusters in VB. The left panel simulates P0 preparations with dye deposits 0.75 equivalent barrels apart; the middle panel simulates P0 preparations with deposits 1.5 barrels apart; and the right panel simulates P4 preparations with deposits in adjacent barrels. Circles with crosses in the P4 panel represent double-labeled cells. Note the similarity between simulated and experimentally observed patterns (Fig. 3). See Materials and Methods and Results for details on the assumptions underlying the simulation. $E$, The probability and segregation indices calculated for simulated patterns generated by 10 consecutive runs of the simulation. Each run generated a triplet of patterns, similar to those illustrated in $D$. Comparison of pancls $C$ and $E$ shows a good quantitative agreement between experiment and simulation, suggesting that the assumptions used in the simulation were sufficient to account for the experimental results.
} 


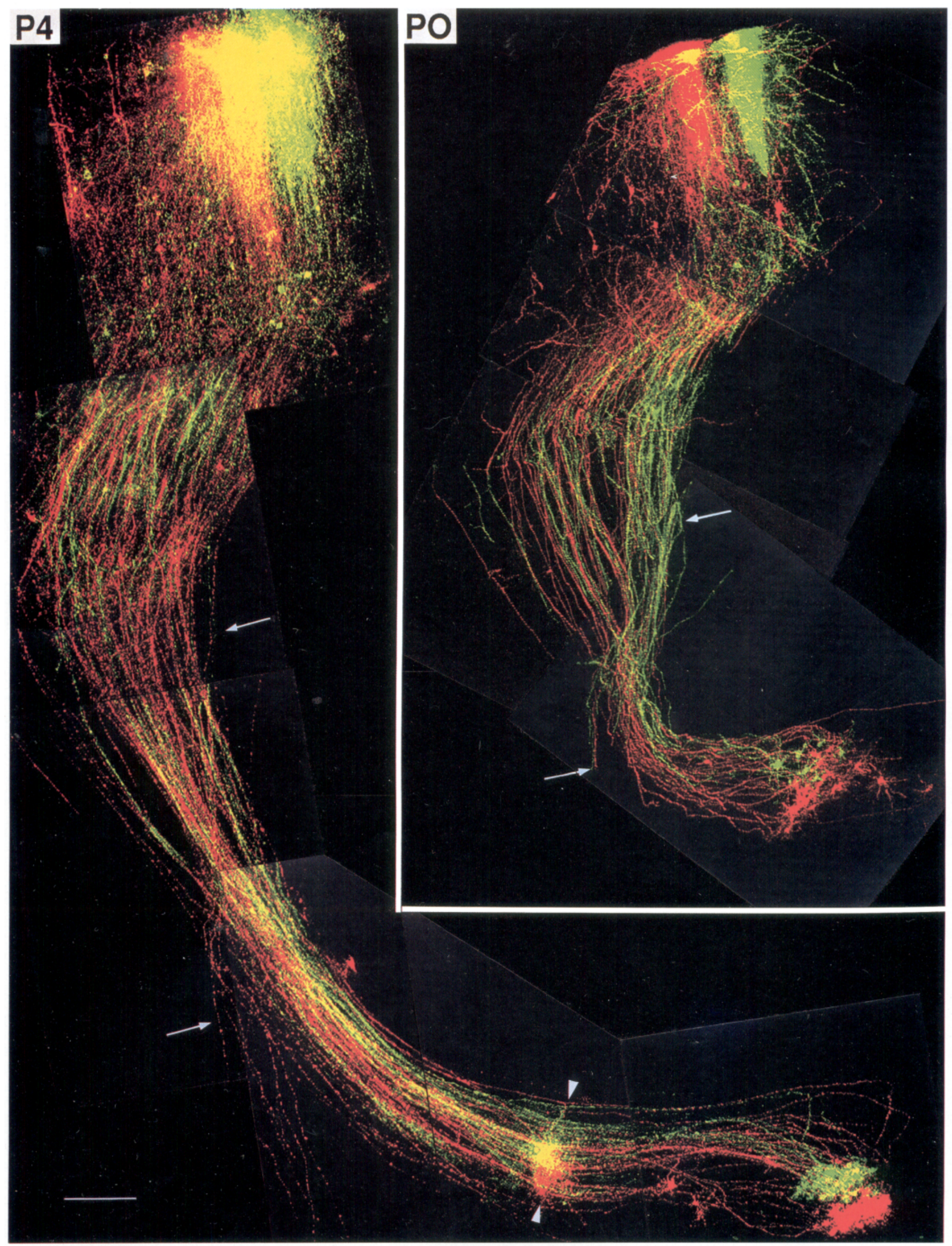


separates the cclls into two groups that are least likely to arise by a random permutation of all colors. To that end we define the $M E D I A N$ point of each cluster as the point with its three coordinates being, respectively, the medians of the $x, y, z$-coordinates of the cells in the cluster. We test sequentially a series of planes orthogonal to the line between the two medians and intersecting this line at intervals equal to $1 / 10$ the intermedian distance. Each plane divides the labeled cells into two subsets, subset $\boldsymbol{a}$ and subset $\boldsymbol{b}$, each dominated by one of the two colors. The number of cells of each color on either side of a given plane is calculated by forming the radius vector to each cell from the intersection point of the plane with the line between the medians, and projecting the vector on this line (similar to Eq. 2, with the median of each cluster substituted for its center of mass); cells with positive projections are to the right of the plane (say, in subset $a$ ), cells with negative projections are to its left (in $\boldsymbol{b}$ ). Assume that there are $\mathbf{K}$ red cells in subset $\boldsymbol{a}$. Given the total number of cells in each of the two subsets as $\mathbf{A}$ and $\mathbf{B}$, respectively, the probability $\mathbf{P}(\mathbf{K})$ that a random permutation of colors between all labeled cells would give rise to exactly $\mathbf{K}$ red cells in subset $\boldsymbol{a}$ (and thus to $\mathbf{R}-\mathbf{K}$ red cells in subset $\boldsymbol{b}$, $A-\mathbf{K}$ green cells in $\boldsymbol{a}$, and $\mathbf{G}-\mathbf{A}+\mathbf{K}$ green cells in $\boldsymbol{b}$ ) is, from basic combinatorics,

$$
\begin{aligned}
\mathbf{P}(\mathbf{K}) & =\frac{\left(\begin{array}{l}
\mathbf{R} \\
\mathbf{K}
\end{array}\right) \cdot\left(\begin{array}{c}
\mathbf{G} \\
\mathbf{A}-\mathbf{K}
\end{array}\right)}{\left(\begin{array}{c}
\mathbf{A}+\mathbf{B} \\
\mathbf{A}
\end{array}\right)} \\
& =\frac{\mathbf{A} ! \cdot \mathbf{B} !}{(\mathbf{A}+\mathbf{B}) !} \cdot \frac{\mathbf{R} !}{\mathbf{K} !(\mathbf{R}-\mathbf{K}) !} \cdot \frac{\mathbf{G} !}{(\mathbf{A}-\mathbf{K}) ! \cdot(\mathbf{G}-\mathbf{A}+\mathbf{K}) !}
\end{aligned}
$$

We can now define the optimal plane of separation as the plane that minimizes $\mathbf{P}(\mathbf{K})$. (If several sequential planes give rise to the same minimal $P(K)$, we choose a plane in an average position.) Given this optimal plane, we calculate the probability that a degree of segregation equal to or higher than that observed would arise by chance, that is, as a result of a random permutation of all colors. This is the probability that $\mathbf{K}$ or more cells in subset $\boldsymbol{a}$ would be red, if red is the dominant color in $\boldsymbol{a}$, or that $\mathbf{K}$ or less cells in subset $\boldsymbol{a}$ would be red, if green is the dominant color in $\boldsymbol{a}$. This probability is given by

$$
\mathbf{P}(\mathbf{k} \geq \mathbf{K})=\sum_{\mathbf{k}-\mathbf{K}}^{\mathbf{k}=\min (\mathbf{A}, \mathbf{R})} \mathbf{P}(\mathbf{k})
$$

for the first case $(\mathbf{K}>\mathbf{A} / 2)$, or by

$$
\mathbf{P}(\mathbf{k} \leq \mathbf{K})=\sum_{\mathbf{k}=0}^{\mathbf{k}=\mathbf{K}} \mathbf{P}(\mathbf{k})
$$

for the second case $(\mathbf{K}<\mathbf{A} / 2)$. Finally, the probability index P.I. is defined as the negative logarithm of this probability; that is,

$$
\text { P.I.: }=-\log _{10}(\mathbf{P}(\mathbf{k} \geq \mathbf{K}))
$$

for the first case, and similarly for the second case.

\section{Appendix B}

Given two cortical loci, we designate as $\mathbf{D}_{\mathrm{c}}$ the distance between them, and as $D_{t}$ the separation in the thalamus between the centers of mass of the thalamocortical cell clusters projecting to these cortical loci (i.e., the thalamic cells that would be retrogradely labeled from the cortical loci). We next define as $\mathbf{R M S}_{\mathbf{c}}$ the root mean square of the distances within the cortex from the terminals of all axons originating from a given thalamic locus to the center of mass of their distribution, measured parallel to the line connecting the two cortical loci. We further define as $\mathbf{R M S}_{\mathbf{t}}$ the RMS of the distances between thalamocortical cells bodies in each cluster to their center of mass in the thalamus, along the direction connecting the two centers of mass. We then get, from geometrical considerations, the relationship

$$
\frac{\mathbf{R M S}_{\mathrm{c}}}{\mathbf{R M S}_{\mathbf{1}}}=\frac{\mathbf{D}_{\mathrm{c}}}{\mathbf{D}_{\mathrm{t}}}
$$

(Both flanks of this equation are equal to the linear magnification factor of the projection.) From this we get

$$
\frac{\mathbf{D}_{\mathrm{t}}}{\mathbf{R M S}_{\mathrm{t}}}=\frac{1}{\mathbf{R M S}_{\mathbf{c}}} \mathbf{D}_{\mathbf{c}}
$$

The left flank of this equation is equal to our segregation index. Thus $\mathbf{R M S}_{\mathbf{c}}$ is the reciprocal of the slope of the segregation index versus dye separation plot. Assuming a random distribution of axon terminals around their precise topological target, $\mathbf{R M S}_{\mathbf{c}}$ is the RMS of the point spread function of the projection. This assumption holds on P0, but not on P4 and later, since axons originating from any point within a barreloid will distribute around the center of their corresponding barrel, and not around their precise topological target.

\section{Appendix C}

We want to calculate the RMS of the point spread function of the adult thalamocortical projection. We assume that in the mature system a thalamocortical axon arborizes homogeneously throughout its target barrel, and that all cells in a given barreloid project to the same barrel. The contribution of any given thalamic neuron to the point spread function is a step function, one barrel wide, centered anywhere from $1 / 2$ barrel to the left to $1 / 2$ barrel to the right of its precise topological target point, depending on its location within its barreloid. Taking the center of the barrel as axis origin in the cortex, the center of the corresponding barreloid as axis origin in the thalamus, and 1 as both barrel and barreloid diameters, the probability that an axon originating in position $t$ in the thalamus will innervate a point

\footnotetext{
Figure 5. The thalamocortical pathway in a P0 (right) and a P4 (left) preparation. Montages of low-power (10x objcctive) confocal images of slices labeled by dual dye deposits in adjacent loci in the upper cortical layers. DiI(3)-labeled structures are pseudocolored green, DiI(5)-labeled structures are pseudocolored red. Yellow represents (in most cases) spatial overlap of red and green structures, not double labeling of the same structures with both dyes. In the P4 slice there were eight double-labeled cells in VB (out of 95); in the P0 preparation there were none (out of 30). Note that differentially labeled thalamocortical axons are intermixed along most of the pathway, but their cell bodies are well-segregated in VB, and (on P4) their collateral ramifications are well-segregated in RTN (between arrowheads). Two aberrant DiI(5) labeled cells are visible in the P4 preparation, halfway between the labeled barreloids and RTN. Corticofugal fibers (truncated, between arrows) cross the main bundle of thalamocortical axons from medial to lateral. Dorsal is up, lateral is left. Scale bar, $250 \mu \mathrm{m}$.
} 
in the cortcx, $\mathbf{x}$ units away from its precise topological target, is therefore given by

$$
\mathbf{p}(\mathbf{x}, \mathbf{t})= \begin{cases}1 & (-\mathbf{t}-1 / 2 \leq \mathbf{x} \leq-\mathbf{t}+1 / 2) \\ 0 & \text { otherwise }\end{cases}
$$

The point-spread function $\mathrm{P}(\mathrm{x})$ of the thalamocortical projection is given by adding the contributions of all cells in a barreloid; that is,

$$
\mathbf{P}(\mathbf{x})=\int_{-1 / 2}^{1 / 2} \mathbf{p}(\mathbf{x}, \mathbf{t}) \mathbf{d t}= \begin{cases}1-|\mathbf{x}| & (-1 \leq \mathbf{x} \leq 1) \\ 0 & \text { otherwise }\end{cases}
$$

$\mathbf{P}(\mathbf{x})$ is a symmetric triangular function with a width of 2 and a height of 1 . Its RMS is given by

$$
\mathbf{R M S}=\left(\int_{-1}^{1} \mathbf{x}^{2} \cdot \mathbf{P}(\mathbf{x}) \mathbf{d x}\right)^{1 / 2}=\sqrt{\frac{1}{6}}
$$

or $\mathrm{RMS}=0.41$

\section{References}

Agmon A, Connors BW (1991) Thalamocortical responses of mouse somatosensory (barrel) cortex in vitro. Neuroscience 41:365-379.

Agmon A, Yang LT, O'Dowd DK, Jones EG (1993) Organized growth of thalamocortical axons from the deep tier of terminations into layer IV of mouse barrel cortex. J Neurosci 13:5365-5382.

Andres FL, Van der Loos H (1985) From sensory periphery to cortex: the architecture of the barrelfield as modified by various early manipulations of the mouse whiskerpad. Anat Embryol (Berl) 172:1120.

Belford GR, Killackey HP (1979a) Vibrissae representation in subcortical trigeminal centers of the neonatal rat. J Comp Neurol 183 305-364.

Belford GR, Killackey HP (1979b) The development of vibrissae representation in subcortical trigeminal centers of the neonatal rat. J Comp Neurol 188:63-74.

Bernardo KL, Woolsey TA (1987) Axonal trajectories between mouse somatosensory thalamus and cortex. J Comp Neurol 258:542-564.

Bicknese AR, Sheppard AM, O'Leary DDM, Pearlman AL (1994) Thalamocortical axons extend along a chondroitin sulfate proteoglycan-enriched pathway coincident with the neocortical subplate and distinct from the efferent path. J Neurosci 14:3500-3510.

Catalano SM, Robertson RT, Killackey HP (1991) Early ingrowth of thalamocortical afferents to the neocortex of the prenatal rat. Proc Natl Acad Sci USA 88:2999-3003.

Catalano S, Robertson RT, Killackey HP (1993) Morphology of individual thalamic afferents in early postnatal rat somatosensory cortex. Soc Neurosci Abstr 19:674.

Chiaia NL, Fish SE, Bauer WR, Bennett CC, Rhoades RW (1992) Postnatal blockade of cortical activity by tetrodotoxin does not disrupt the formation of vibrissa-related patterns in the rat's somatosensory cortex. Brain Res Dev Brain Res 66:244-250.

Chiaia NL, Crissman RS, Bennet-Clarke CA, Rhoades RW (1993) Axonal transport blockade mimics effects of neonatal infraorbital nerve transection upon vibrissae-related patterns. Soc Neurosci Abstr 19:1107.

Crandall JE, Caviness VS (1984) Thalamocortical connections in newborn mice. J Comp Neurol 228:542-556.

Dawson DR, Killackey HP (1985) Distinguishing topography and somatotopy in the thalamocortical projections of the developing rat. Brain Res 349:309-313.

Erzurumlu RS, Jhaveri S (1990) Thalamic axons confer a blueprint of the sensory periphery onto the developing rat somatosensory cortex. Brain Res Dev Brain Res 56:229-234.

Erzurumlu RS, Jhaveri S (1992) Trigeminal ganglion cell processes are spatially ordered prior to the differentiation of the vibrissa pad J Neurosci 12:3946-3955.

Fox K (1992) A critical period for experience-dependent synaptic plasticity in rat barrel cortex. J Neurosci 12:1826-1838.

Fox K, Schlaggar BL, O'Leary DDM (1993) The effect of post-synaptic activity blockade on development of barrel cortex. Soc Neurosci Abstr 19:616.
Gierer A (1987) Directional cues for growing axons forming the retinotectal projection. Development 101:479-489.

Henderson TA, Woolsey TA, Jacquin MF (1992) Infraorbital nerve blockade from birth does not disrupt central trigeminal pattern formation in the rat. Brain Res Dev Brain Res 66:146-152.

Holt CE, Harris WA (1993) Position, guidance, and mapping in the developing visual system. J Neurobiol 24:1400-1422.

Hope RA, Hammond BJ, Gaze RM (1976) The arrow model: retinotectal specificity and map formation in the goldfish visual system. Proc R Soc Lond [Biol] 194:447-466.

Horder TJ, Martin KAC (1978) Morphogenetics as an alternative to chemospecificity in the formation of nerve connections. In: Cell-cell recognition, 32nd Symp Soc Exp Biol (Curtis ASG, ed), pp 275-358. Cambridge: Cambridge UP.

Ivy GO, Killackey HP (1982) Ephemeral cellular segmentation in the thalamus of the neonatal rat. Brain Res 254:1-17.

Jeanmonod D, Rice FL, Van der Loos H (1977) Mouse somatosensory cortex: development of the alterations in the barrel field which are caused by injury to the vibrissal follicles. Neurosci Lett 6:151-156.

Jensen KF, Killackey HP (1987) Terminal arbors of axons projecting to the somatosensory cortex of the adult rat. I. The normal morphology of specific thalamocortical afferents. J Neurosci 7:3529-3543.

Jhaveri S, Erzurumlu RS, Crossin K (1991) Barrel construction in rodent neocortex: role of thalamic afferents versus extracellular matrix molecules. Proc Natl Acad Sci USA 88:4489-4493.

Kageyama GH, Robertson RT (1993) Development of geniculocortical projections to visual cortex in rat: evidence for early ingrowth and synaptogenesis. J Comp Neurol 335:123-148.

Killackey HP, Jacquin MF, Rhoades RW (1990) Development of somatosensory system structures. In: Development of sensory systems (Coleman JR, ed), pp 403-429. New York: Wiley.

Land PW, Simons DJ (1985) Metabolic and structural correlates of the vibrissae representation in the thalamus of the adult rat. Neurosci Lett 60:319-324.

Lorente de Nó R (1922) La corteza cerebral del raton. Trab Inst Cajal Invest Biol 20:41-78. English translation: The cerebral cortex of the mouse (Fairén A, Regidor J, Kruger L, trans). Somatosens Motor Res 9:3-36, 1992.

Ma PM (1991) The barrelettes-architectonic vibrissal representations in the brainstem trigeminal complex of the mouse. I. Normal structural organization. J Comp Neurol 309:161-199.

Miller B, Chou L, Finlay BL (1993) The early development of thalamocortical and corticothalamic projections. J Comp Neurol 335:1641.

Miller KD (1990) Correlation-based models of neural development. In: Neuroscience and connectionist theory (Gluck MA, Rumelhart DE, eds), pp 267-353. Hillsdale, NJ: Erlbaum.

Naegele JR, Jhaveri S, Schneider GE (1988) Sharpening of topographical projections and maturation of geniculocortical axon arbors in the hamster. J Comp Neurol 277:593-607.

Nakamura H, O'Leary DD (1989) Inaccuracies in initial growth and arborization of chick retinotectal axons followed by course corrections and axon remodeling to develop topographic order. J Neurosci 9:37763795.

Nelson SB, LeVay S (1985) Topographic organization of the optic radiation of the cat. J Comp Neurol 240:322-330.

Rice FL, Van der Loos H (1977) Development of the barrels and barrel field in the somatosensory cortex of the mouse. J Comp Neurol 171:545-560.

Sanes JR (1993) Topographic maps and molecular gradients. Curr Opin Neurobiol 3:67-74.

Schlaggar BL, Fox K, O'Leary DD (1993) Postsynaptic control of plasticity in developing somatosensory cortex. Nature 364:623-626.

Senft SL, Woolsey TA (1991a) Growth of thalamic afferents into mouse barrel cortex. Cereb Cortex 1:308-335.

Senft SL, Woolsey TA (1991b) Computer-aided analyses of thalamocortical afferent ingrowth. Cereb Cortex 1:336-347.

Senft SL, Woolsey TA (1991c) Mouse barrel cortex viewed as Dirichlet domains. Cereb Cortex 1:348-363.

Simon DK, O'Leary DD (1992a) Development of topographic order in the mammalian retinocollicular projection. J Neurosci 12:12121232.

Simon DK, O'Leary DD (1992b) Influence of position along the medial-lateral axis of the supcrior colliculus on the topographic targeting and survival of retinal axons. Brain Res Dev Brain Res 69:167-172. 
Sims PJ, Waggoner AS, Wang CH, Hoffman JF (1974) Studies on the mechanisms by which cyanine dyes measure membrane potential in red blood cells and phosphatidylcholine vesicles. Biochemistry 13: 3315-3330.

Sperry RW (1963) Chemoaffinity in the orderly growth of nerve fiber patterns and connections. Proc Natl Acad Sci USA 50:703-710.

Sretavan DW, Shatz CJ (1987) Axon trajectories and pattern of terminal arborization during prenatal development of the cat's retinogeniculate pathway. J Comp Neurol 255:386-400.

Stirling RV (1991) Molecules, maps and gradients in the retinotectal projection. Trends Neurosci 14:509-512.

Sugitani M, Yano J, Sugai T, Ooyama H (1990) Somatotopic organization and columnar structure of vibrissae representation in the rat ventrobasal complex. Exp Brain Res 81:346-352.

Thanos S, Bonhoeffer F (1987) Axonal arborizations in the developing chick retinotectal system. J Comp Neurol 261:155-164.

Udin SB, Fawcett JW (1988) Formation of topographic maps. Annu Rev Neurosci 11:289-327.

Van der Loos H (1976) Barreloids in mouse somatosensory thalamus. Neurosci Lell 2:1-6.
Van der Loos H, Dorfl J (1978) Does the skin tell the somatosensory cortex how to construct a map of the periphery? Neurosci Lett 7:2330.

Welker E, Van der Loos H (1986) Quantitative correlation between barrel-field size and the sensory innervation of the whiskerpad: a comparative study in six strains of mice bred for different patterns of mystacial vibrissae. J Neurosci 6:3355-3373.

Willshaw DJ, von der Malsburg C (1976) How patterned neural connections can be set up by self-organization. Proc R Soc Lond [Biol] 194:431-445.

Woodward WR, Chiaia N, Teyler TJ, Leong L, Coull BM (1990) Organization of cortical afferent and efferent pathways in the white matter of the rat visual system. Neuroscience 36:393-401.

Woolsey TA (1990) Peripheral alterations and somatosensory development. In: Development of sensory systems (Coleman JR, ed), pp 461-516. New York: Wiley.

Woolsey TA, Van der Loos H (1970) The description of a cortical field composed of discrete cytoarchitectonic units. Brain Res 17:205242. 